\title{
TRAINING GENERAL PSYCHIATRY RESIDENTS IN CHILD AND ADOLESCENT PSYCHIATRY
}

Eugene V. Beresin, M.D. and Jonathan Sugar, M.D.

The authors describe the nature of current social and economic forces impacting on the education and future practice of general psychiatry residents in child and adolescent psychiatry. They review theoretical and practical reasons for training in child and adolescent psychiatry, analyze the form and content of what is currently taught based on a national survey of general training programs, and suggest guidelines for the training and postgraduate practice of general psychiatrists in evaluating and treating children and adolescents. The authors conclude that while social and economic changes necessitate general psychiatrists' clinical involvement with children and adolescents, insufficient general training may necessitate postgraduate education and supervision. They pose ethical and professional dilemmas for the field in meeting the national shortage of child and adolescent psychiatrists and propose strategies to enhance recruitment into child and adolescent residency training.

Eugene V. Beresin, M.D., is Director of General and Child \& Adolescent Psychiatry Residency Training, Massachusetts General Hospital and Instructor in Psychiatry, Harvard Medical School. Jonathan Sugar, M.D., is Director of Pediatric Liaison Psychiatry and Lecturer in Psychiatry, University of Michigan Medical Center.

Address reprint requests to Eugene V. Beresin, M.D., Dept. of Psychiatry, Bulfinch 3, Massachusetts General Hospital, 55 Fruit Street, Boston, MA 02114. 


\section{INTRODUCTION}

There are few areas in psychiatry where social, economic and political forces impact more than in the training, education, and practice of child and adolescent psychiatry. The current need for child and adolescent services far outweighs the provider pool.1,2 Yet, there are fewer medical students entering psychiatry, ${ }^{3}$ and further into child and adolescent residency training. ${ }^{4}$ Moreover, there are significant shortages in child and adolescent faculty necessary to educate trainees throughout their careers, both graduate and undergraduate. ${ }^{2,5}$ This bleak picture is complicated by current drastic cutbacks in the economics of health care benefits throughout the public and private sectors.

In the face of this crisis in child and adolescent psychiatric manpower and practice, the field is facing critical practical, theoretical and ethical dilemmas. Given the inadequate pool of child and adolescent psychiatrists, who will care for our ill children and adolescents? Are general psychiatrists adequately equipped to provide their necessary inpatient and outpatient evaluation and treatment? Finally, the current move toward subspecialization ${ }^{6}$ is drawing more and more trainees away from general and child and adolescent practice. Is the national opportunity for subspecialization in adolescent psychiatry, with prospective certification from the American Board of Adolescent Psychiatry, a close affiliate of the American Society of Adolescent Psychiatry, going to help or hinder the care and treatment of children and adolescents, the recruitment of child and adolescent psychiatry faculty, and provision of a critical mass of needed researchers in the field?

The purpose of this paper is to clarify the vital current dilemmas outlined above in hopes of promoting discussion at all local and national levels; to explore the theoretical and practical needs for training general psychiatrists in child and adolescent psychiatry; to suggest basic recruitment strategies to increase the number of child and adolescent psychiatrists; to present an overview of the child and adolescent psychiatry curriculum currently taught in general psychiatry training programs; and finally, to provide some practical guidelines for the acquisition of knowledge and skills so that general psychiatrists may deliver competent limited care to children and adolescents. 


\section{WHY TEACH CHILD AND ADOLESCENT PSYCHIATRY IN GENERAL PSYCHIATRY RESIDENCY TRAINING PROGRAMS?}

Child and adolescent psychiatry knowledge is relevant in the training of general psychiatrists for myriad reasons, both theoretical and practical. Practically, due to the shortage of child and adolescent psychiatrists, it is likely that general psychiatrists will continue to be involved in the evaluation and/or in the treatment of children and adolescents. Theoretically, knowledge about children and human growth, especially biological, cognitive, and emotional development, is fundamental to theories of personality, psychopathology, and psychotherapy used throughout all clinical practice, teaching, and research.

The need for increased psychiatric services for children and adolescents is well documented. At least $12 \%$ of those under 18 years of age in the United States have diagnosable mental illness. ${ }^{7}$ Child and adolescent suicide is on the rise, peaking at 16 per 100,000 for white males, aged 15 to $19 .^{8}$ Services are needed for the victims, and possibly perpetrators, of urban violence including the dealing and use of drugs, gang warfare, incest and rape. It is now generally accepted that disorders such as depression, obsessive-compulsive disorder, eating disorders, and panic disorders, occur among children as well as adults.

There are simply not enough child and adolescent psychiatrists to meet this need. The Graduate Medical Education National Advisory Commission (GMENAC) report of 1980 found that 9,000 child psychiatrists would be needed in order to meet clinical need in the year $1990 .{ }^{1}$ While Enzer notes that the GMENAC estimates were based on figures of $8.6 \%$ of children requiring professional help, a percentage substantially below other estimates, ${ }^{2,7}$ even the optimistic current estimate of 6,000 child and adolescent psychiatrists practicing in the United States falls far short of the conservative GMENAC target. ${ }^{2}$ Moreover, GMENAC did not include need for educators, researchers, or administrators. ${ }^{2}$ How this gap between need and fully trained providers, educators, and administrators will be met is a discussion beyond the scope of this paper; suffice to say that there is an ethical dilemma that must be faced as to who is best suited to treat children and adolescents with 
psychiatric disorders and that, depending on geographic availability of child and adolescent psychiatrists, general psychiatrists will be called on more or less to treat children and adolescents directly and in consultation.

General psychiatrists in practice encounter child psychiatric issues in many areas. Physicians in most states are mandated reporters of child abuse to state protective agencies, and psychiatrists may hear of such abuse from their patients. The behavior of patients' children may become a focus of psychotherapy, and the clinician will need to recognize child and adolescent pathology in order to provide appropriate counseling or referral. In addition, as more knowledge about the vertical transmission and heritability of psychiatric disorders becomes available, practicing psychiatrists will be called upon to discuss with their adult patients the risks to offspring.

At root, psychiatry remains committed to treating the whole patient. The role of past experiences, including childhood experiences, in patients' self perceptions cannot be overemphasized. This perspective is reflected in the history of psychiatric thought. From Dora $^{9}$ to Three Essays on Sexuality, ${ }^{10}$ Freud emphasized the import of childhood and child development of psychic processes and psychopathology. Adolph Meyer, throughout his work, felt that life experiences, including childhood, had direct impact on the development of psychiatric disease. ${ }^{11,12,13}$ Erikson posits childhood building blocks upon which identity and well being are based, ${ }^{14}$ and the object relations schools of psychotherapy ${ }^{15}$ are heavily influenced by findings and theory in human development, particularly Mahler's findings on separation-individuation. ${ }^{16}$ Newer developmental models have had a profound impact on our understanding of the role of temperament and psychobiology, 17,18 and parent-child interactions on child development and adult psychopathology and need for treatment. ${ }^{19,20,21}$

Empirical findings from epidemiology to genetics are underscoring the role of childhood in adult psychiatric disease. Bowlby ${ }^{11}$ posits a "developmental psychiatry," based upon human development, ethology, and current life experiences, that seeks to explain the onset and course of psychiatric disease in individuals. Reiss, ${ }^{22}$ in his review of behavioral genetics and psychiatric illness, highlights that early experiences are responsible for at least $50 \%$ of the expression of genetic predisposition in certain psychiatric disor- 
ders. The impact of childhood trauma, ${ }^{23}$ prolonged separation from parents, ${ }^{24}$ social inhibition, ${ }^{25}$ attention deficit disorder, ${ }^{26}$ and divorce ${ }^{27}$ often have a direct relationship to adult psychopathology.

Clearly, some theoretical and practical understanding of children, their development, and childhood and adolescent psychopathology is necessary in adult work. Moreover, there is great clinical value in teaching general psychiatry residents about family structure, family development and ethnicity. The critical issue is for psychiatric educators and certifying bodies to decide on the form, content, quantity and goals of material to be presented to and learned by general psychiatry residents.

Teaching child and adolescent psychiatric knowledge and skills should also enhance recruitment into the specialty training of child and adolescent psychiatry. Weissman and Bashook found that although $30 \%$ of medical school graduates applying in psychiatry express an interest in child and adolescent psychiatry, this figure drops to $18 \%$ by the PGY 4 level. ${ }^{28}$ Currently, approximately $13 \%$ of general psychiatry residents enter child and adolescent residencies. ${ }^{4}$

There are many reasons postulated for the poor recruitment of child and adolescent residents. Child and adolescent psychiatry has long suffered from an image problem, viewed by many physicians as having a "soft" clinical and scientific base. ${ }^{29,30,31}$ It has been severely devalued by general psychiatry, internal medicine, and pediatric subspecialties. ${ }^{2,5}$ Traditionally, there has been considerable distance between the child guidance clinics and general teaching hospitals..$^{32}$ For general residents, there is often late exposure to child and adolescent patients along with early attachment to general residency clinicians and research; ${ }^{5}$ lack of close contact and identification with child psychiatry faculty;2,29,30,33 fear of poor clinical compensation, excessive time demands, and shrinking research funds; ${ }^{30}$ and pressure to stay on to fill senior residency slots. Moreover, psychiatry residents, along with trainees in all specialties, are facing increasing indebtedness from medical school, resulting in pressure to curtail extended residencies, such as child and adolescent training, and obtain more lucrative practice positions or shorter, attractive subspecialty training, e.g. geriatrics, forensics, substance abuse, etc.

The great hope of teaching quality child and adolescent psychiatry and providing faculty role models in general psychiatry resi- 
dencies is both to inspire residents to care for our nation's youth, and to assume leadership positions in academia. Unfortunately, while a cadre of strong faculty mentors is reportedly the single most important draw into child and adolescent training, ${ }^{3}$ there is only a limited national pool of trained talent. There are many cited reasons for a shortfall in child and adolescent faculty: the lack of their own faculty mentors and research projects in which to participate;5,29,30,33 poor collaboration with ongoing research projects in general psychiatry; lack of institutional incentives to pursue academic careers (e.g., time, stipends, promotions, facilities); poor relations between child and adolescent psychiatry training programs and general psychiatry training programs; excessive clinical and academic demands; and disincentives for part-time faculty, including many talented women, who cannot compete for grants and institutional incentives.

Thus, teaching child and adolescent psychiatry early in medical school and residency training, providing adequate exposure to high quality faculty role models and mentors, dispelling the negative image of child and adolescent psychiatry, and establishing important collaborative clinical and research bridges between general and child and adolescent psychiatry will all enhance the learning process for general residents and potentially increase recruitment into child and adolescent psychiatry.

\section{NATIONAL GUIDELINES FOR TEACHING CHILD AND ADOLESCENT PSYCHIATRY}

The Accreditation Council of Graduate Medical Education (ACGME) outlines basic principles for teaching child and adolescent psychiatry in general psychiatry residency training programs, but these guidelines seriously lack specificity. They are quite broad and allow for a variety of resident experiences in different training sites. ${ }^{34}$ Hence, one cannot draw adequate conclusions regarding clinical or academic competency among general psychiatrists for any child or adolescent practice on the basis of meeting these criteria. Practice standards are set by such processes as peer review and local institutional quality assurance committees. Some national organizations, such as the American Academy of Child and Adolescent Psychiatry (AACAP), set and update practice parameters for the field in the treatment of specific disorders. 


\section{DATA FROM THE 1989 AMERICAN ASSOCIATION OF DIRECTORS OF PSYCHIATRIC RESIDENCY TRAINING (AADPRT) SURVEY}

The 1989 "annual" survey sponsored by the AADPRT represented only $49 \%$ of all accredited psychiatry residency programs, but appears to have covered a good cross-section of large and small, urban and rural programs. Hence, the sample provides some picture of what is actually taught in general training programs.

On average, general psychiatry training programs have approximately four full-time, two part-time, and five voluntary child and adolescent psychiatrists providing the clinical and didactic training. Sixty-eight percent were affiliated with a child and adolescent training program, and $38 \%$ had vacant, funded faculty child and adolescent psychiatry positions. Approximately two general residents from each program yearly entered child and adolescent residencies.

Table 1 summarizes the general residency supervised clinical experience and Table 2 outlines the scope of didactic seminars. In terms of clinical experiences, over $80 \%$ of programs provided reasonable exposure to outpatient diagnostic evaluations, short-term individual psychotherapy, child and adolescent psychopharmacology, and family therapy, though the number of cases were limited, except perhaps for diagnostic evaluations. Approximately $65 \%$ of programs exposed residents to inpatient treatment, long-term psychotherapy and emergency psychiatry, but, again, the number of cases were few. Strikingly, 54\% of programs had no training in observation of normal children, and approximately one-third had no exposure to behavior therapy or consultation-liaison psychiatry. Clearly, one would not expect a graduate of the "average" general training program to do much more than diagnostic evaluations (which probably occur on inpatient, outpatient, and emergency services).

A summary of the average didactic curricula in general psychiatry training programs demonstrates that a number of important topics are given very little time, including pediatric psychopharmacology (4 sessions), substance abuse ( 2.4 sessions), individual psychotherapy (6.2 sessions), mental retardation (2.2 sessions), developmental disabilities (2.6 sessions), and consultation-liaison psychiatry (5.4 sessions). While most important topics are pre- 


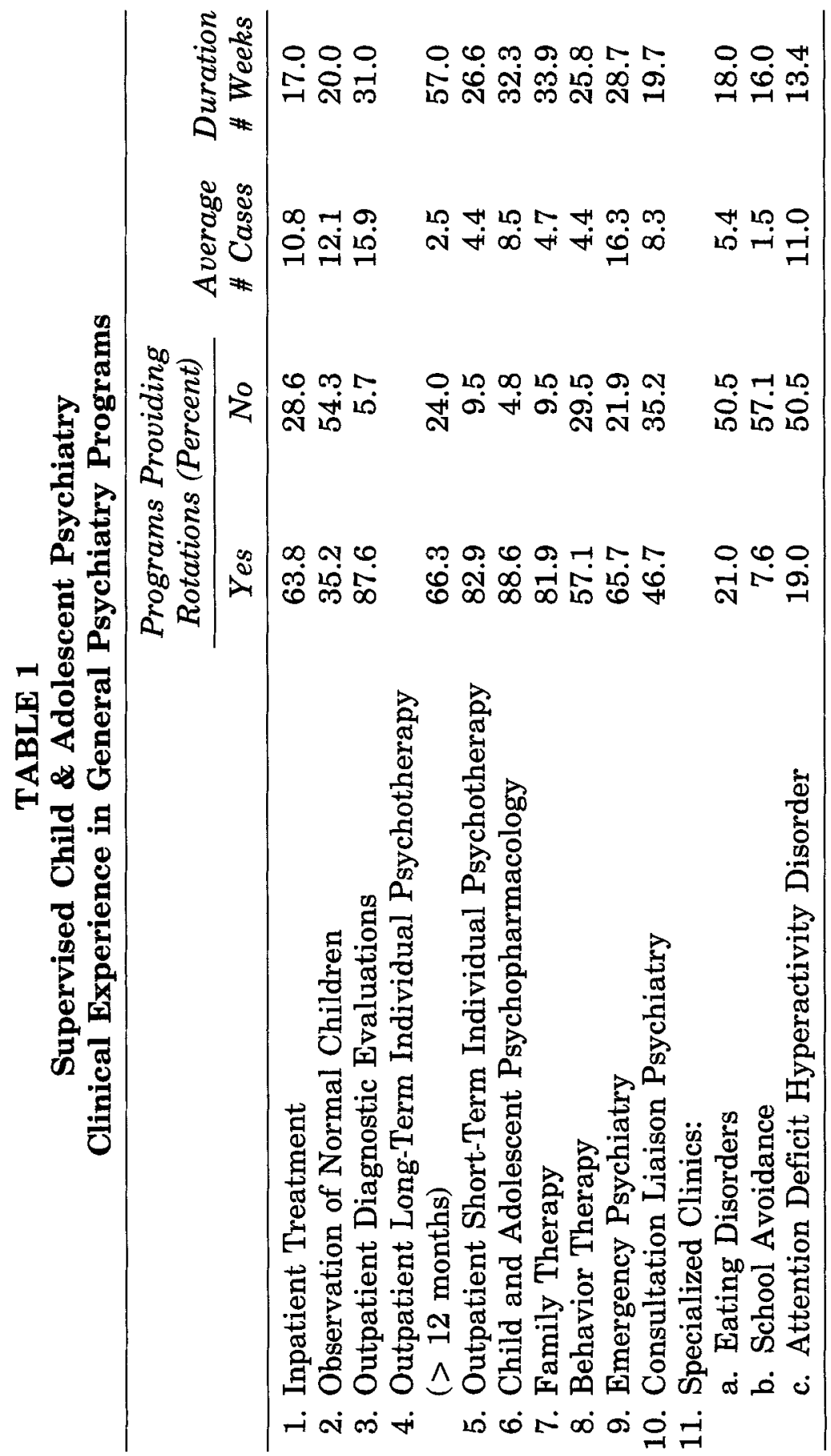




\section{TABLE 2}

Didactic Seminars in General Psychiatry Programs

\begin{tabular}{|c|c|c|c|}
\hline & \multicolumn{2}{|c|}{$\begin{array}{c}\text { Programs Providing } \\
\text { Seminars (Percent) }\end{array}$} & \multirow{2}{*}{$\begin{array}{l}\text { Average \# } \\
\text { of Sessions }\end{array}$} \\
\hline & Yes & No & \\
\hline 1. Infant Development & 86.7 & 4.8 & 4.4 \\
\hline 2. Child Development & 90.5 & 0 & 6.8 \\
\hline $\begin{array}{l}\text { 3. Adolescent Development } \\
\text { 4. Pediatric }\end{array}$ & 86.7 & 3.8 & 4.9 \\
\hline Psychopharmacology & 85.5 & 1.9 & 4.0 \\
\hline 5. Substance Abuse & 61.9 & 17.1 & 2.4 \\
\hline \multicolumn{4}{|l|}{ 6. Child Abuse and } \\
\hline Neglect & 80.0 & 5.7 & 2.0 \\
\hline 7. Family Structure & 81.9 & 5.7 & 5.7 \\
\hline 8. Adoption and Custody & 46.2 & 31.7 & 1.7 \\
\hline \multicolumn{4}{|l|}{ 9. Individual } \\
\hline Psychotherapy & 76.2 & 9.5 & 6.2 \\
\hline 10. Family Therapy & 78.1 & 8.6 & 10.7 \\
\hline 11. Consultation-Liaison & 48.6 & 28.6 & 5.4 \\
\hline 12. Mental Retardation & 69.5 & 16.2 & 2.2 \\
\hline \multicolumn{4}{|l|}{ 13. Developmental } \\
\hline Disabilities & 72.4 & 11.4 & 2.6 \\
\hline \multicolumn{4}{|l|}{ 14. Social \& Community } \\
\hline Psychiatry & 46.7 & 28.6 & 2.8 \\
\hline 15. Epidemiology & 36.5 & 38.5 & 1.7 \\
\hline 16. Psychological Testing & 64.8 & 16.2 & 3.2 \\
\hline 17. Sleep Disorders & 40.0 & 32.4 & 2.1 \\
\hline 18. Enureses \& Encopresis & 70.5 & 13.3 & 1.7 \\
\hline 19. Eating Disorders & 76.2 & 9.5 & 3.4 \\
\hline \multicolumn{4}{|l|}{ 20. Attention Deficit } \\
\hline Hyperactivity Disorder & 82.9 & 4.8 & 2.1 \\
\hline 21. Mood Disorders & 81.9 & 5.7 & 2.4 \\
\hline 22. Anxiety Disorders & 82.9 & 4.8 & 2.0 \\
\hline 23. Conduct Disorders & 82.9 & 3.8 & 2.4 \\
\hline 24. Behavior Therapy & 49.5 & 27.6 & 2.1 \\
\hline \multicolumn{4}{|l|}{ 25. Developmental } \\
\hline Neurobiology & 41.0 & 30.5 & 1.8 \\
\hline 26. Ethnicity & 29.5 & 43.8 & 1.4 \\
\hline
\end{tabular}


sented, the knowledge base taught in seminars is low. Of course, much didactic teaching may be conducted on clinical services and in supervision; thus, the general residents' knowledge base may well be much broader than these figures demonstrate. Nevertheless, it is not at all convincing that many should be deemed competent clinically in working with children and adolescents upon graduation from a general residency based on the above findings.

\section{REASONABLE BASIC EDUCATIONAL OBJECTIVES FOR THE GENERAL PSYCHIATRY RESIDENT}

Noting the relative paucity of clinical and didactic experiences currently offered, one should set rather limited objectives for the general residents' acquisition of knowledge and skill. However, given the clinical needs expressed earlier, and the likelihood that some generalists will be evaluating and treating children and adolescents, educators should take those numbers seriously and strongly consider expanding clinical and academic provisions if at all possible.

At this juncture, it seems most reasonable to set the following objectives for understanding child and adolescent psychiatry as it pertains to working clinically with adolescents, youth and families:

Knowledge Base

1. Child and adolescent development, including normal biological, psychological, behavioral and social developmental milestones.

2. Contributions of major theorists, clinicians, and researchers.

3. Child and adolescent psychopathology, including all DSMIIIR syndromes.

4. Family structure and systems.

5. Psychological evaluations available, including intelligence, developmental, personality, and projective tests.

6. Therapeutic interventions available, including complete diagnostic evaluations, individual long and short-term psycho- 
therapy, behavioral and family therapy, and pharmacotherapy.

Skills

1. Conduct a competent psychiatric interview with children, adolescents, and families.

2. Develop a comprehensive formulation/evaluation of children and adolescents, including biological, cognitive, psychodynamic, social and familial components. Articulate DSMIIIR differential diagnosis. Above all, determine youth at risk and determine appropriate disposition (e.g. psychotherapy, pharmacotherapy, hospital, social service, court, etc.)

3. Order appropriate psychological, medical, and laboratory tests to aid the clinical evaluation.

4. Assess the local health care system to know what services are available.

5. If the resident has sufficient clinical experience and supervision (e.g. taking electives over and above the "average" experience expressed in Tables 1 and 2) initiate and conduct appropriate dynamic, behavioral, family and/or pharmacotherapy utilizing expert consultants liberally.

6. Refer the child and/or family for necessary psychiatric, social, medical, educational, and community services.

7. Collaborate with other expert members of a child and adolescent health care system including pediatricians, child and adolescent psychiatrists, psychologists, social workers, nurses, teachers, and other professionals to provide a comprehensive evaluation and treatment program.

Imparting these basic objectives depends largely on what is available in one's training institution and/or region. They can be taught either in inpatient or outpatient settings along with some exposure to community agencies. If a critical mass of competent child and adolescent faculty is not available at one's home training site, consortia should be developed to share resources, such as clinical and academic faculty. It is advisable to start the learning process early, both from the standpoint of broadening work with 
adults, increasing exposure to children and adolescents and, hopefully, exposing residents to mentors early in their training so as to increase chances of recruitment into child and adolescent residency training. If a resident plans to become a general psychiatrist and knows he or she is likely to be evaluating and/or treating children, high quality electives in both inpatient and outpatient settings should be developed, covering a wide net of age ranges and diagnostic groups. Individual careful and creative planning with the training director is essential for this process. Finally, the program should inculcate the ethical and professional standard that if the generalist's core training program was insufficient to meet his or her clinical needs in practice, one should seek postgraduate education and supervision.

\section{DISCUSSION}

If we consider the overwhelming clinical and academic needs of child and adolescent psychiatry, a critical goal of general residency training should be to enhance recruitment into child and adolescent residencies. For the general psychiatrist who chooses not to subspecialize, numerous personal dilemmas must be realistically appraised. One must carefully assess whether he or she is capable of providing more than a competent diagnostic evaluation and, if not, decide how and where to get additional instruction on treatment technique. The current recession, coupled with decreased insurance reimbursements for mental health workers will certainly lead the population to non-MD health professionals, who can provide services for lower costs. As a profession, we have to decide what we want our role to be in the treatment of children and adolescents.

The dilemmas raised are both ethical and practical. We close with our opening question: Who will care for our children, adolescents and families? Is there enough substance in general psychiatry training programs or in pediatrics for graduates to do a good, competent job, not simply in basic diagnostic evaluations but in continuity of care? We conclude that there are severe limitations for the general psychiatrist in the practice of child and adolescent psychiatry. General residency training as it currently exists is insufficient for competently treating children, young adolescents 
and families. At this time, the best we can expect is for utilization of basic child and adolescent training during general residency for thorough evaluation and triage of youth and families and help in working with adult patients, along with vigilance in determining their children at risk.

General residents follow career paths based on educational experiences which are both personally enjoyable, and, as noted by Dewey, which "live fruitfully and creatively in subsequent experiences." 35 Inspiring academic experiences are also crucial in choosing subspecialization. It is our hope that the joy of working with children and adolescents will spread and that research advances will stimulate academic interest in the field. We cannot overestimate the value of enthusiastic mentors in bolstering recruitment into child and adolescent psychiatry. Action must be taken at local and national levels to create financial and research incentives toward this end.

\section{REFERENCES}

1. Graduate Medical Education National Advisory Committee (GMENAC): Report of the Graduate Medical Education National Advisory Committee, DHHS pub no (HRA) 81-651. Washington, D.C., Department of Health and Human Services, 1980.

2. Enzer NB: Recent trends in the recruitment of child and adolescent psychiatrists: an overview of general and faculty needs. Academic Psychiatry 13:176-188, 1989.

3. Association of American Medical Colleges: Statistical Information Related to Medical Education. Washington, D.C., 1991.

4. Rowley BD, Baldwin DC, McGuire MB, et al.: Graduate medical education in the United States. Journal of the American Medical Association, 264:822-832, 1990.

5. Beresin EV, Borus JF: Child psychiatry fellowship training: a crisis in recruitment and manpower. American Journal of Psychiatry, 146:759-763, 1989.

6. Yager J: Issues in general residency training pertinent to recruitment of child psychiatrists: can we identify the problems? Academic Psychiatry 13:202-207, 1989.

7. Committee of the Institute of Medicine, Division of Mental Health and Behavioral Medicine: Research on Children and Adolescents with Mental, Behavioral and Developmental Disorders: Mobilizing a National Initiative. Washington, D.C., National Academy Press, 1989. 
8. Shaffer D, Garland A, Gould M, et al.: Preventing teenage suicide: a critical review. Journal of the American Academy of Child and Adolescent Psychiatry, 27:675-687, 1988.

9. Freud S: Fragment of an analysis of a case of hysteria ("Dora"), in The Freud Reader, Edited by Gay P. New York, Norton, 1989.

10. Freud S: Three essays on the theory of sexuality in The Freud Reader, Edited by Gay P. New York, Norton, 1989.

11. Bowlby J: Developmental psychiatry comes of age. American Journal of Psychiatry, 145:1-10, 1988.

12. Havens L: Approaches to the Mind. Cambridge, Massachusetts, Harvard University Press, 1987.

13. Weiner MF: Theories of personality and psychopathology: other psychodynamic schools, in Comprehensive Textbook of Psychiatry, 5th ed., vol. one. Edited by Kaplan HI, Sadock BJ. Baltimore, Williams \& Wilkins, 1989.

14. Erikson EH: Childhood and Society. New York, Norton, 1963.

15. Kernberg O: Object Relations Theory and Clinical Psychoanalysis. New York, Jason Aronson, 1976.

16. Mahler M, Pine F, Bergman A: The Psychological Birth of the Human Infant. New York, Basic Books, 1975.

17. Chess S, Thomas A: Temperament in Clinical Practice. New York, Guilford Press, 1986.

18. Kagan J: The Nature of the Child. New York, Basic Books, 1984.

19. Stern DN: The Interpersonal World of the Infant. New York, Basic Books, 1985.

20. Greenspan SI: Emotional and developmental patterns in infancy, in Handbook of Clinical Assessment of Children and Adolescents, vol. 1, Edited by Kestenbaum CJ, Williams DT. New York, New York University Press, 1988.

21. Zeanah CH, Anders TF, Seifer, et al.: Implications of research on infant development for psychodynamic theory and practice. Journal of the American Academy of Child and Adolescent Psychiatry, 20:657-668, 1989.

22. Reiss D, Plomin R, Hetherington EM: Genetics and psychiatry: an unheralded window on the environment. American Journal of Psychiatry, 148:283-291, 1991.

23. Terr LC: Childhood traumas: an outline and overview. American Journal of Psychiatry, 148:10-12, 1991.

24. Brown G, Harris T: The Social Origins of Depression: A Study of Psychiatric Disorder in Women. New York, Free Press, 1978.

25. Rosenbaum JF, Biederman J, Gersten M, et al.: Behavioral inhibition in children of parents with panic disorder and agoraphobia. Archives of General Psychiatry, 45:463-470, 1988.

26. Weiss G, Hechtman LT: Hyperactive Children Grown Up. New York, Guilford Press, 1986.

27. Wallerstein JS: Children of divorce: the psychological tasks of the child, in Annual Progress in Child Psychiatry and Child Development, Edited by Chess S, Thomas A. New York, Brunner/Mazel, 1985.

28. Weissman SH, Bashook PG: A view of the prospective child psychiatrist. American Journal of Psychiatry, 143:722-727, 1986. 
29. Philips I, Cohen RL, Enzer NB: Child Psychiatry: A Plan for the Coming Decades. Washington, D.C., American Academy of Child Psychiatry, 1983.

30. Shapiro T, Campbell M, Garfinkle B, et al.: Report on the Work Group on Scientific Issues. Washington, D.C., American Academy of Child and Adolescent Psychiatry, 1989.

31. Detre T: Some comments on the future of child and adolescent psychiatry. Academic Psychiatry, 13:189-195, 1989.

32. Earls F: The future of child psychiatry as a medical discipline. American Journal of Psychiatry, 139:1158-1161, 1982.

33. Beresin E, Enzer N: Conference issues and recommendations to improve recruitment efforts, in Preparing for the Future: Recruitment in Child and Adolescent Psychiatry: Recommendations from the 1989 San Diego Conference, Edited by Schowalter, J. Washington, D.C., HCA Psychiatry Company, 1990.

34. Directory of Graduate Medical Education Programs. Chicago, American Medical Association, 1988.

35. Dewey J: Experience and Education. New York, Collier Books, 1938. 